\title{
ANÁLISE MULTICRITÉRIO NA INDÚSTRIA DE PEÇAS AUTOMOTIVAS: UM ESTUDO DE CASO UTILIZANDO O MÉTODO PROMÉTHÉE
}

\author{
Sérgio Luiz Pinto Pereira ${ }^{1}$ \\ Luiz Flavio Autran Monteiro Gomes, PhD $^{2}$
}

\section{Resumo}

O presente trabalho apresenta o estudo de caso no qual é aplicado um método de apoio multicritério à tomada de decisão para um problema relativo a contratação de uma empresa externa para resolver um problema de software. A empresa estudada atua na área de fabricação e venda de peças para o mercado automotivo e possui uma estrutura de informática que foca suas atividades no entendimento do negócio do cliente e na proposta de soluções, utilizando a compra de software ou o desenvolvimento de programas, por meio da prestação de serviços. O estudo demonstra como a utilização de um método de apoio à tomada de decisão apresenta uma clara visão do problema, permitindo aos decisores analisar as informações iniciais e a realizar ajustes nos pesos e nos critérios utilizados na tomada de decisões, de forma a refletir sobre as melhores opções. O método escolhido, no caso, o Prométhée, apresenta-se também como uma ferramenta adequada à análise de situações em contextos decisórios semelhantes.

Palavras-chave: Estudo de caso - método multicritério de apoio à tomada de decisão solução de software

\begin{abstract}
This article presents a case study in which a multi-criteria decision support method was applied to a problem concerning the contracting of an external company to solve a software problem. The company studied operates in the area of manufacture and sale of car parts and has an information technology structure which focuses its activities on understanding the client's business and proposing solutions, using the purchase of software or the development of programs, via the provision of services. The study demonstrates that the use of a decision support method allows a clear vision of the problem, enabling decision-makers to analyze the initial information and perform adjustments to the weights/criteria used in decision making so
\end{abstract}

\footnotetext{
${ }^{1}$ Mestre em Administração

Pesquisador Associado, Faculdades Ibmec/RJ

Av. Rio Branco, 108, quinto andar, CEP 20040-001

Rio de Janeiro, RJ, e-mail: slppereira@bol.com.br

${ }^{2}$ Doutor,Professor titular das Faculdades Ibmec/RJ

Av. Rio Branco, 108, quinto andar, CEP 20040-001

Rio de Janeiro, RJ, e-mail: autran@ibmecrj.br
} 
as to reflect the best options. The method chosen is also presented as an analysis tool for similar situations.

Key-words: Case study - multi-criteria decision support method - software solution

\section{INTRODUÇÃo}

Das diversas áreas possíveis de terceirização, a tecnologia da informação (TI) é uma das que mais está mudando o seu perfil de trabalho a fim de incorporar o conceito de outsourcing. Diversas empresas de desenvolvimento e suporte estão se desenvolvendo especificamente para esse mercado. Nesse contexto complexo e novo, os gerentes de nível médio das empresas que irão utilizar estes serviços encontram-se diante do desafio de escolha de quais áreas terceirizar e com quais empresas trabalhar. Esses novos desafios apresentam-se como tarefas complexas e importantes.

A empresa em estudo é do ramo de fornecimento de peças para o mercado automotivo, e terá sua identidade preservada. Essa empresa, nos últimos três anos, fez um grande investimento em informatização para seus sistemas operacionais, comprando software básicos (ERP e CRM) e contratando serviços de suporte ao desenvolvimento e implantação desses sistemas.

O presente trabalho é resultado da necessidade real da contratação de uma empresa externa para a prestação de serviço de manutenção ou evolução do software de ERP, conhecidos como pacotes de gestão empresarial. O dilema atual é a definição dos critérios e pesos que serão utilizados para a escolha de qual empresa prestará este serviço.

\section{O PROBLEMA}

\subsection{A Empresa em Estudo e o Processo de Informatização}

A empresa a ser analisada é uma empresa multinacional, com a fabricação tanto para a utilização na indústria quanto para o mercado de reposição. Atua em um mercado altamente competitivo, estando alternadamente entre a primeira e segunda posição na classificação mundial de empresas do seu setor. Apresenta-se em 170 países, com um parque industrial mundial de 80 fábricas e uma rede de distribuição em nível mundial. Seu mercado constituise de peças para automóveis de passeio, grandes veículos de carga e transporte, veículos agrícolas, veículos de engenharia civil, trens metroviários, veículos de duas rodas, bicicletas e aviões. Na América do Sul, possui três fábricas no Brasil e duas na Colômbia.

Apresenta em sua unidade administrativa da América do Sul com centralização administrativa no Brasil para seu departamento de TI. Na sua metodologia de trabalho, analisa, para qualquer projeto, se a melhor opção é o desenvolvimento/produção interno ou a compra de produtos/serviço. Para a sua unidade administrativa da América do Sul já foi definido que os produtos ou serviços de infra-estrutura, help desk, operação de CPD e manutenção ou desenvolvimento de software são comprados.

Para desenvolvimento de soluções de software, a terceirização hoje atua em todas as fases, mais fortemente na consultoria para implantação de pacotes e no desenvolvimento de programas. Na manutenção, a terceirização trabalha com pacotes implantados e com programas desenvolvidos por encomenda.

A empresa contratante trabalha hoje com um grupo médio de 10 empresas contratadas, podendo, dependendo da demanda, aumentar ou diminuir esse grupo. 
As definições quanto à utilização de empresas externas trouxe a preocupação da melhor escolha para contratação. As experiências recentes demonstram a necessidade de uma ferramenta que possa expressar o inter-relacionamento de todas as questões consideradas importantes para a escolha, de uma "memória de cálculo" na tomada de decisão e de um histórico que possa ser utilizado como consulta para futuras escolhas.

A situação atual é de insatisfação quanto ao processo utilizado e de necessidade de utilização de métodos padronizados, simples, flexíveis e de fácil utilização.

\subsection{O Processo de Decisão Atual}

A empresa contratante utiliza uma metodologia de pesquisa e avaliação. Nessa metodologia, a etapa de pesquisa é utilizada para a definição dos critérios a serem considerados e a análise dos possíveis candidatos à solução, gerando uma pré-seleção das melhores opções (normalmente 3 empresas/produtos). Na etapa de avaliação, é escolhida a melhor opção. Essa metodologia é definida para qualquer tipo de compra ou contratação de serviços de TI. Ela apresenta a definição do que fazer, não definindo, porém, um método padrão de comparação entre alternativas, o que gera uma diversificação nos processos utilizados.

\subsection{O Estudo de Caso}

O caso em questão está relacionado à escolha de uma empresa para a manutenção de um software de gestão empresarial, um sistema de ERP que foi comprado e parametrizado na empresa. O processo de compra e implementação durou dois anos, e todo trabalho de definição de funcionamento e parametrização do sistema foi desenvolvido em parceria com uma empresa de consultoria. A questão atual é a definição de qual empresa será contratada para manter este pacote. A manutenção foi definida como técnica (desenvolvimento e correção de programas) e funcional (correção de parametrizações funcionais e novas parametrizações).

\section{ESTRUTURAÇÃO MULTICRITÉRIO DO PROBLEMA}

\subsection{Definição Inicial dos Critérios de Análise}

A gerência responsável pela escolha da empresa a ser contratada definiu a preocupação com os seguintes itens gerais:

- Experiência no que é requisitado - expertise no processo de manutenção no pacote em questão; Característica do projeto - projeto que apresenta características rotineiras (manutenção do funcionamento do sistema) e não rotineiras (desenvolvimento de novas funcionalidades), segundo a definição de Simcsik (Bernstorff apud Simcsik, 2001). As caraterísticas serão tratadas como manutenções corretivas e adaptativas;

- Benchmarking de trabalhos realizados em outras empresas;

- Potencialidade para o desenvolvimento de outros trabalhos - poder contar com uma empresa que possa ter escalabilidade, com potencialidade para suprir uma possível nova demanda em nível América do Sul;

- Metodologia de desenvolvimento e gerência de projetos - a empresa deve apresentar uma metodologia definida e compatível com a metodologia da empresa contratante, tanto no desenvolvimento quanto no gerenciamento dos projetos; 
- Abrangência - capacidade de suprir a demanda de toda a América Latina, não apenas do Brasil;

- Preço - melhor preço na realização do trabalho;

- Postura profissional - trabalhos já realizados que tenham demonstrado que a empresa é flexível quanto a questões de contrato;

- Parceria - histórico de comportamento flexível quanto às necessidades da contratante. Critério definido a partir do histórico de trabalhos da empresa com a contratada, onde em situações de exceção, as demonstrações de objetivos comuns e de condutas de solução de problemas foram mais fortes do que a postura de renegociação de contrato;

- Saúde financeira;

- Experiência profissional da equipe disponibilizada pelo terceiro no desenvolvimento do projeto - identificação e avaliação das pessoas que participarão do desenvolvimento pela empresa contratada.

A gerência responsável considerou estes critérios importantes a partir da sua experiência na contratação de outras empresas. Os itens apresentados foram analisados especificamente para a situação do caso de manutenção de pacote ERP, fazendo uma préseleção de empresas. Os resultados foram:

- Característica do projeto - em um projeto de manutenção, a metodologia e a experiência dos profissionais são pré-condições. Foram selecionadas empresas que apresentaram métodos de trabalho e formação da equipe compatíveis com a empresa contratante, com a experiência de perfis de profissionais definida como necessária (supervisor, número de analistas sênior, pleno e júnior);

- Benchmarking, postura profissional e parceria - avaliado o comportamento das empresas em pelo menos dois clientes atuais;

- Potencialidade para o desenvolvimento de outros trabalhos e abrangência - considerada a possibilidade de evolução dos trabalhos (escalabilidade) para a manutenção dos pacotes em outros países da América do Sul;

- Saúde financeira - Foram consideradas empresas com a saúde financeira compatível com o nível de segurança considerado mínimo pela contratante;

- Experiência no que é requisitado - foram definidos dois tipos diferentes de experiência, no pacote de mercado e na parametrização realizada no pacote especificamente para a empresa contratante;

- Preço - foram considerados os valores de custo de manutenção adaptativa e corretiva, tanto técnica como funcional.

\subsection{Definição dos Critérios de Avaliação}

Para que os critérios escolhidos possam representar de maneira adequada o problema real é necessário que sejam avaliados pelos princípios de exaustividade, coesão e nãoredundância e de independência entre critérios (Gomes et al., 2002). Os critérios considerados, após a verificação daqueles quatro princípios, foram os seguintes:

- Experiência no pacote;

- Experiência no pacote parametrizado da empresa contratante;

- Escalabilidade;

- Custo da manutenção corretiva técnica;

- Custo da manutenção adaptativa técnica;

- Custo da manutenção corretiva funcional; 
- Custo da manutenção adaptativa funcional.

\subsection{Definição dos Atores}

Foram selecionadas seis empresas. O processo de escolha levou em consideração as empresas que já prestaram serviços à contratante ou que já demonstraram interesse em trabalhar em conjunto, além do perfil de conhecimento desejado. Por motivo de confidencialidade, serão identificadas de 'action1' até 'action6'. Das empresas analisadas, três já trabalham com a contratante. Essas empresas foram pré-aprovadas nas seguintes condições:

- Metodologia de desenvolvimento e gerência de projeto compatível com a contratante;

- Grupo de trabalho com a composição e experiência profissional mínima exigida pela contratante;

- Saúde financeira da empresa compatível com o nível de segurança considerado mínimo pela contratante;

- Reconhecimento da postura profissional por pelo menos dois clientes atuais;

\section{MÉTODOS ANALÍTICOS UTILIZADOS}

\subsection{O Método Promethée}

O método Prométhée (Preference Ranking Organization Method for Enrichment Evaluations) é um método da escola francesa de tomada de decisão, desenvolvido pelos professores J.P. Brans, B. Mareschal e P. Vincke, em 1984, e aperfeiçoado desde então.

A escolha do método é resultado da sua objetividade e flexibilidade. Consideramos que a utilização rápida, a fácil verificação, a transparência nos resultados e a flexibilização do processo de comparação foram fatores fundamentais na escolha desse método. É uma ferramenta que tanto pode ser aplicada em grupos como individualmente.

Segundo Scharling (1996) e Vincke (1989), o Prométhée é um método de subordinação, que consiste em construir uma relação de superação entre as alternativas.

Atribuindo a cada critério um peso proporcional a sua importância, calcula-se, para cada par $(a, b)$ de ações, o grau de superação:

$$
\pi(a, b)=\frac{1}{P} \sum_{j=1} p_{j} F_{j}(a, b) \quad \text { onde } P=\sum_{j=1} p_{j}
$$

onde :

- $\mathrm{Pj}$ : peso do critério $\mathrm{j}$;

- Fj(a,b): número compreendido entre 0 e 1, definido pelo critério de comparação;

Neste método, são consideradas seis possíveis comparações entre as ações [a] e $[b]$, que determina o resultado da função $\mathrm{Fj}(\mathrm{a}, \mathrm{b})$.

Pela definição de Brans e Mareschal (2002) sendo $\operatorname{dj}(a, b)=f(a)-f(b)$ podemos definir uma função $\operatorname{Pj}[\operatorname{dj}(a, b)]$ como sendo o grau de preferência de $[a]$ sobre $[b]$. Estas funções de preferência são: 


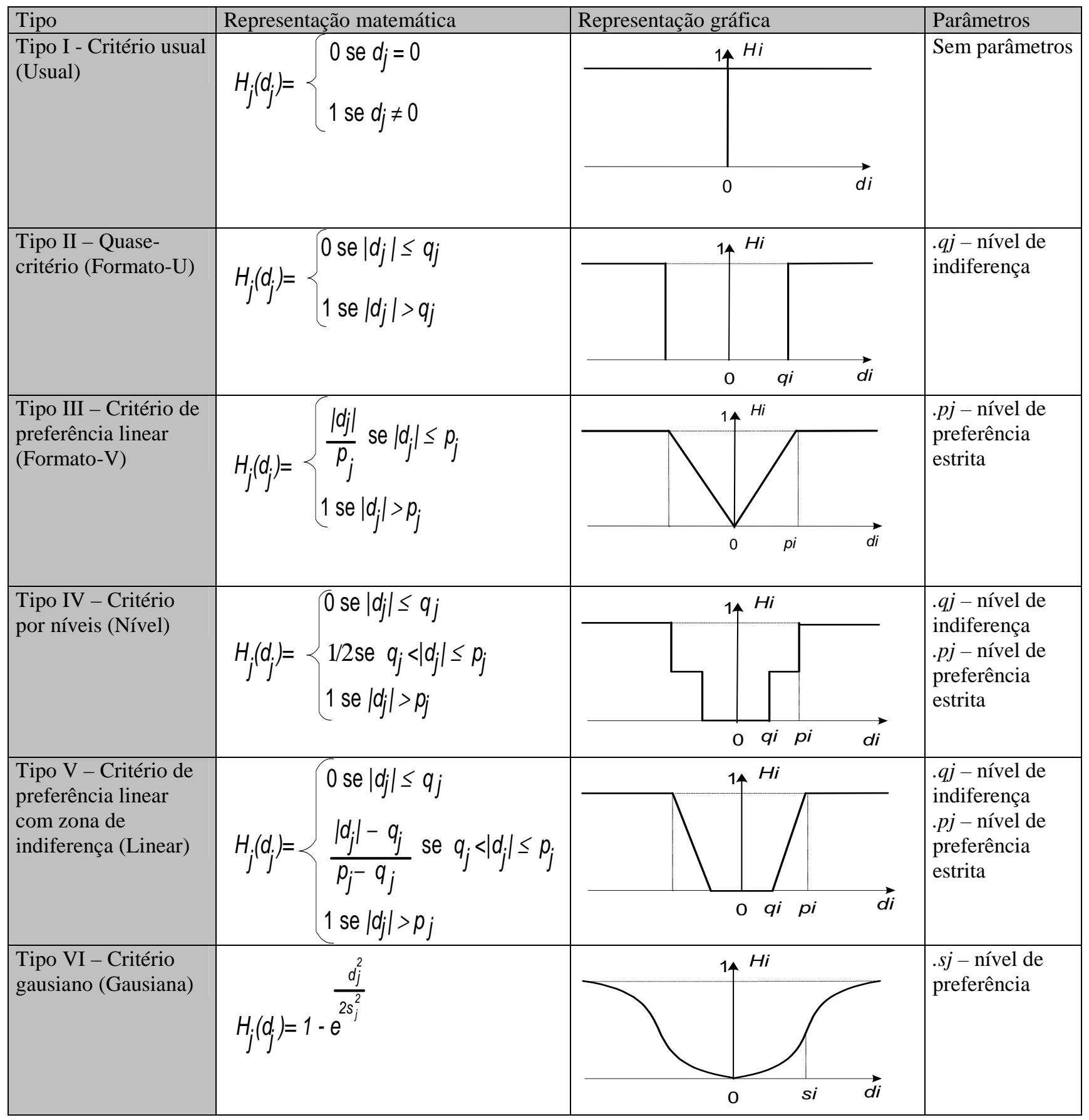

Tabela 1 : Funções de preferência do método Promethée

A comparação é feita tanto de $[a]$ para $[b]$ quanto de $[b]$ para $[a]$.

Com a avaliação entre todas as alternativas para todos os critérios, são construídas duas preordens, uma consistindo na ordem onde a alternativa $[a]$ supera as demais e outra, onde a mesma alternativa $[a]$ é superada pelas todas as outras alternativas. Esses valores resultam do somatório de todas as avaliações por critério de uma determinada alternativa, multiplicada pelos pesos relativos de cada critério e dividido pelo número de alternativas menos um. Com isso teremos a ordenação de superação de uma alternativa sobre todas as 
outras (primeira preordem) e uma segunda ordenação de superação de todas as alternativas sobre essa primeira (segunda préordem).

Segundo Brans e Mareschal (2002), tem-se:

- $\phi^{+}(a)=\sum \pi(a, b)$ (fluxo de superação da ação [a] sobre outras alternativas)

- $\phi^{-}(a)=\sum \pi(b, a)$ (fluxo de superação de todas as outras alternativas sobre ação $[a])$

Os fluxos de superação positivos e negativos permitem a classificação parcial. Para os fluxos de superação positivos apresentam a seguinte preordem:

- $a S^{+} b \Leftrightarrow \phi^{+}(a)>\phi^{+}(b)$

- $a I^{+} b \Leftrightarrow \phi^{+}(a)=\phi^{+}(b)$

Uma ação será melhor tanto quanto seus fluxos positivos forem grandes.

Para os fluxos de superação negativos apresentam a seguinte préordem:

- $a S^{-} b \Leftrightarrow \phi^{-}(a)<\phi^{-}(b)$

- $a I^{-} b \Leftrightarrow \phi^{-}(a)=\phi^{-}(b)$

Uma ação será melhor tanto quanto seus fluxos negativos forem pequenos.

O método Prométhée I constrói uma classificação parcial, utilizando a interseção das duas preordens, onde:

- $\quad a P^{(1)} b([a]$ é preferível à $[b])$ quando:

- $a S^{+} b$ e $a S^{-} b$

- $a S^{+} b$ e $a I^{-} b$

- $a I^{+} b$ e $a S^{-} b$;

- $\quad a I^{(1)} b$ ([a] é indiferente à $\left.[b]\right)$ quando:

- $a I^{+} b$ e $a I^{-} b$;

- $\quad a R^{(l)} b$ ([a] é incomparável à $\left.[b]\right)$ quando:

- $a S^{+} b$ e $b S^{-} a$;

- $b S^{+} a$ e $a S^{-} b$;

$\mathrm{Na}$ comparação parcial, realizada no método Prométhée I, ações que sejam incomparáveis ou indiferentes serão apresentadas, na ordenação, em um mesmo nível (mesma posição) em relação as demais.

A classificação completa , realizada no método Prométhée II, faz-se pelo cálculo da diferença entre o fluxo positivo e o fluxo negativo:

- $(a)=\phi^{+}(a)-\phi^{-}(a)$

$\mathrm{Na}$ comparação completa, ações que sejam indiferentes serão apresentadas, na ordenação, em um mesmo nível (mesma posição) em relação as demais.

Neste trabalho será utilizada a ferramenta Decision Lab®, software desenvolvido pela empresa canadense Visual Decision com base no método Prométhée. A utilização da 
ferramenta torna o processo de simples implementação, onde todos os cálculos do método serão realizados pela ferramenta.

\section{UTILIZAÇÃO DO MÉTODO PARA O PROBLEMA EM QUESTÃO}

\subsection{Definição dos Tipos de Comparação para Cada Critério}

O agente de decisão foi questionado quanto às funções de preferência, parâmetros e escalas de cada critérios. Os critérios finais do modelo ficaram assim definidos:

\begin{tabular}{|l|l|l|l|l|l|}
\hline Critério & Objetivo & Unidade & $\begin{array}{l}\text { Escal } \\
\mathrm{a}\end{array}$ & Preferência & Parâmetros \\
\hline Conhecimento ERP & Maximizar & Conhecimento & $1-5$ & Usual & - \\
\hline Conhecimento ERP contratante & Maximizar & Conhecimento & $1-5$ & Usual & - \\
\hline Escalabilidade & Maximizar & Escalab. & $1-5$ & Formato-V & $\mathrm{p}-2.0$ \\
\hline Manutenção Corretiva Técnica & Minimizar & $\mathrm{R} \$ /$ hora & $0-1$ & Linear & $\begin{array}{l}\mathrm{q}-0.0167 \\
\mathrm{p}-0.0417\end{array}$ \\
\hline Manutenção Adaptativa Técnica & Minimizar & $\mathrm{R} \$ /$ hora & $0-1$ & Linear & $\begin{array}{l}\mathrm{q}-0.0211 \\
\mathrm{p}-0.0526\end{array}$ \\
\hline Manutenção Corretiva Funcional & Minimizar & $\mathrm{R} \$ /$ hora & $0-1$ & Linear & $\begin{array}{l}\mathrm{q}-0.0167 \\
\mathrm{p}-0.0417\end{array}$ \\
\hline Manutenção Adaptativa Funcional & Minimizar & $\mathrm{R} \$ /$ hora & $0-1$ & Linear & $\begin{array}{l}\mathrm{q}-0.0138 \\
\mathrm{p}-0.0345\end{array}$ \\
\hline Parceria & Maximizar & Parceria & $1-5$ & Usual & - \\
\hline
\end{tabular}

Tabela 2: Funções de preferência, escala e parâmetros do caso de estudo

Os valores de custo/hora foram convertidos para percentuais do maior valor apresentado em cada critério. Essa conversão foi realizada em função da confidencialidade das informações. As informações de limites de preferência e indiferença foram convertidos para a mesma escala.

O agente da decisão levou em consideração, também, os seguintes pontos:

- As empresas que não trabalham com a contratante receberam pontuação de Parceria igual a 3 ;

- A empresa que prestou serviços de consultoria para a parametrização do ERP recebeu pontuação igual a 5 em Conhecimento do ERP da contratante. A empresa que trabalhou na geração das interfaces entre o novo sistema e os sistemas legados recebeu pontuação igual a 3. As empresas que participaram do processo de escolha da consultoria para a parametrização do sistema receberam pontuação igual a 2;

- A Escalabilidade está diretamente relacionada com o porte da empresa em análise;

\subsection{Definição dos Pesos}

Questionado sobre os pesos, o agente de decisão definiu os seguintes valores :

- Peso 1 - Escalabilidade, Conhecimento ERP e Parceria;

- Peso 2 - Manutenção Corretiva Funcional;

- Peso 3 - Manutenção Corretiva Técnica;

- Peso 4 - Conhecimento ERP Contratante;

- Peso 5 - Manutenção Adaptativa Funcional;

- Peso 6 - Manutenção Adaptativa Técnica; 
Pela definição de pesos do agente de decisão, teremos o seguinte vetor de pesos $\mathrm{V}_{1}$ : $\mathrm{V}_{1}=[1,0 ; 4,0 ; 1,0 ; 5,0 ; 6,0 ; 2,0 ; 3,0 ; 1,0]$

\subsection{Aplicação dos Dados ao Método}

Os valores alcançados por cada alternativa foram definidos pelo agente de decisão e são apresentados na figura abaixo, entrada do software Decision Lab ${ }^{\circledR}$ :

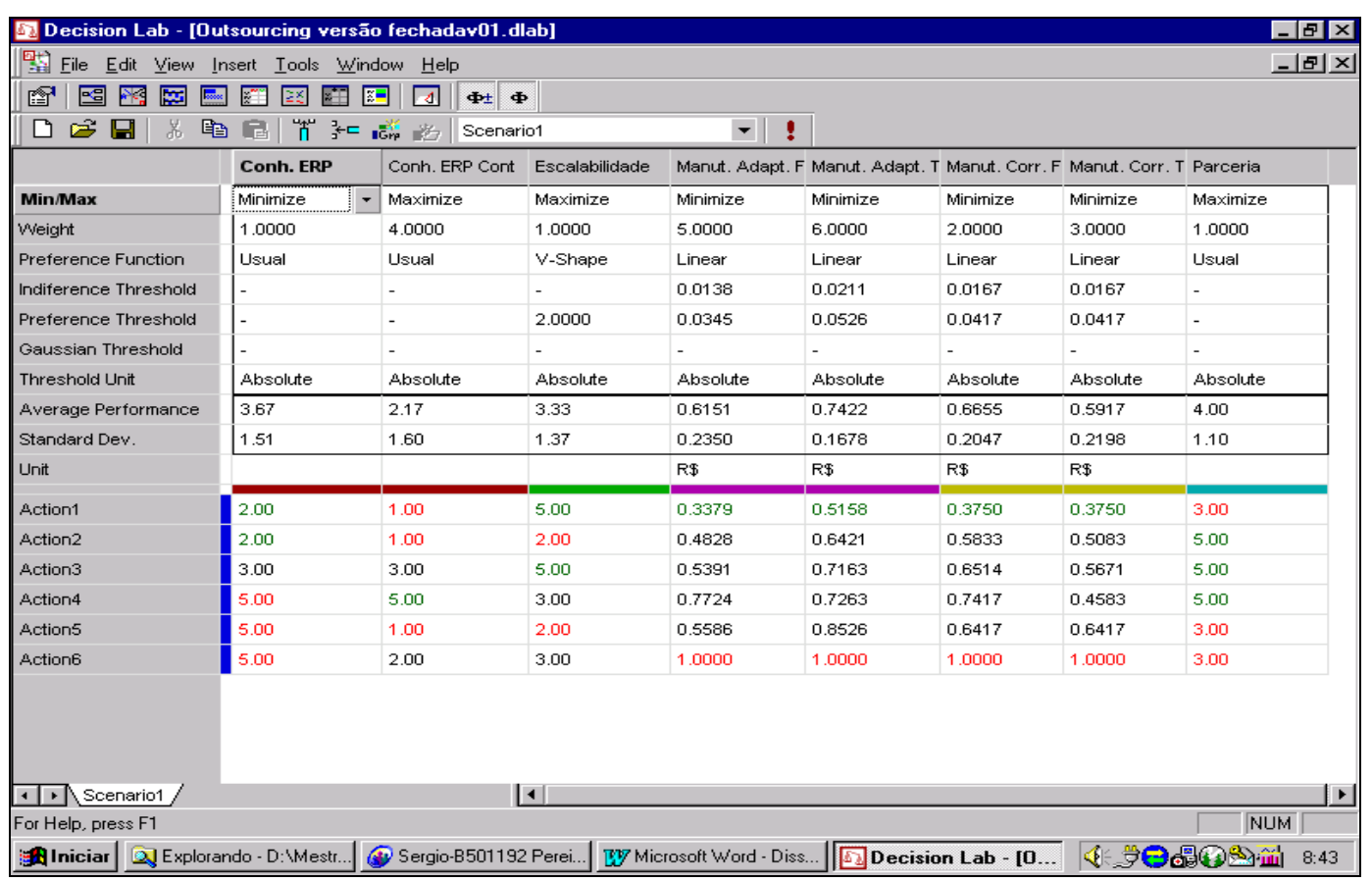

Figura 1: Definições de valores para os critérios e pesos

\subsection{Análise dos resultados}

Os resultados da comparação são apresentados a seguir:

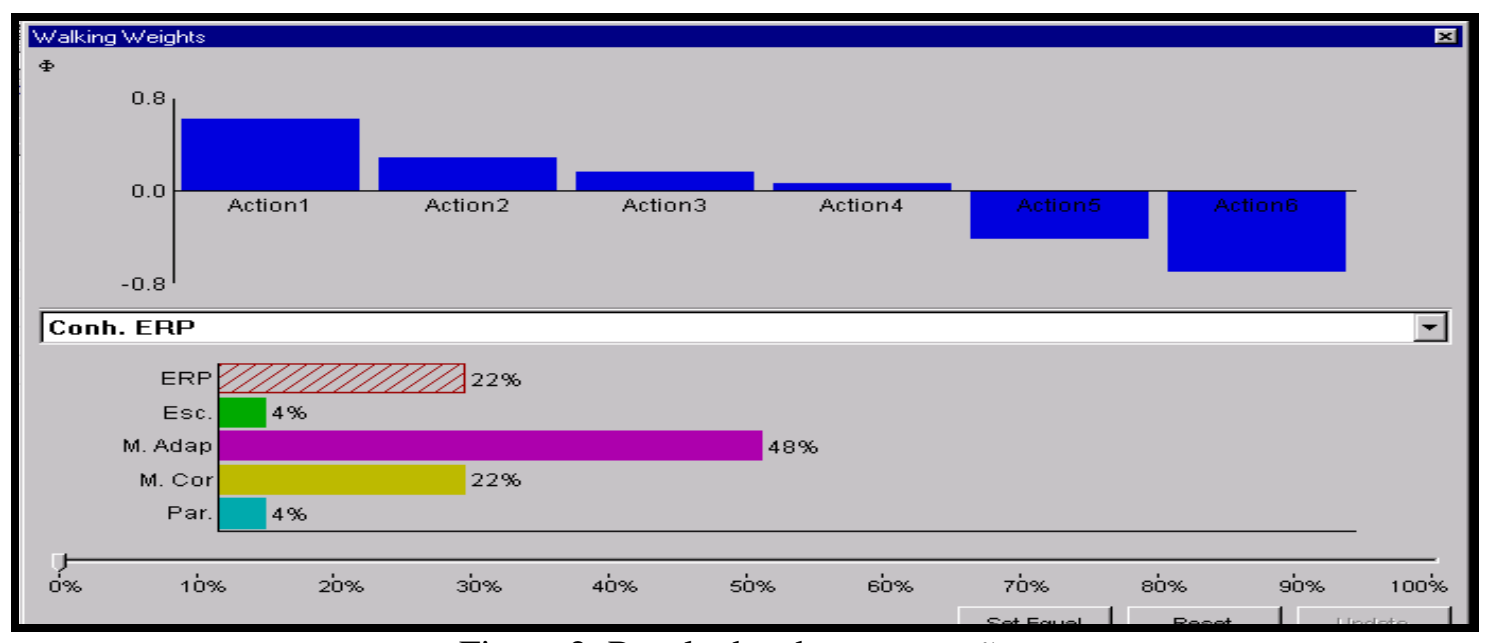

Figura 2: Resultados da comparação 


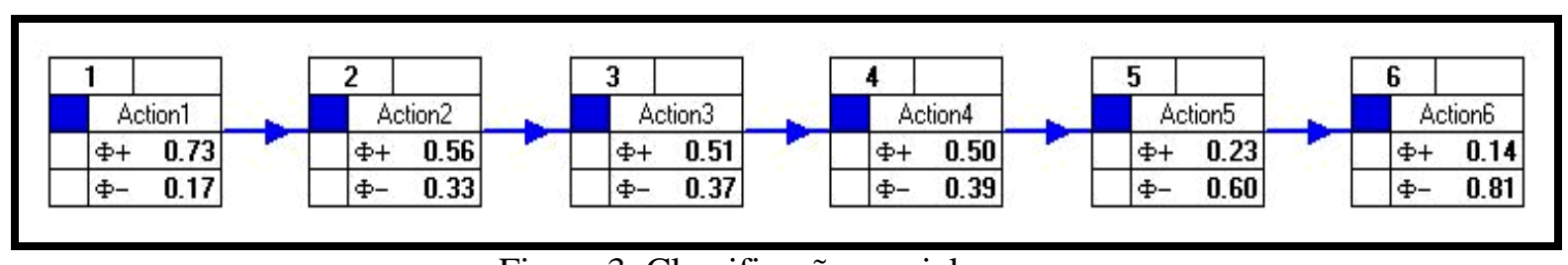

Figura 3: Classificação parcial

O agente de decisão ficou surpreso com o resultado da comparação. Não tinha idéia da definição de $70 \%$ do peso total diretamente relacionado com custos de manutenção. A ferramenta propiciou a visualização dos pesos utilizados e o alinhamento da decisão na direção das informações de custo.

O agente de decisão considerou que os pesos foram mal distribuídos. Considerou que a segurança na contratação de uma empresa que pudesse rapidamente assumir a manutenção do sistema, para o momento , é tão importante quanto o custo. Aumentou os pesos para o Conhecimento do ERP e para o critério de Parcerias, diminuindo o critério de Escalabilidade, que segundo ele não é tão importante para a manutenção do sistema, já que o processamento é centralizado. Os novos pesos foram definidos como segue:

- Peso 1,50 - Conhecimento ERP;

- Peso 3,00 - Conhecimento ERP Contratante;

- Peso 0,50 - Escalabilidade;

- Peso 0,75 - Manutenção Adaptativa e Corretiva (Funcional e Técnica);

- Peso 2,00 - Parceria;

Pela definição de pesos do agente de decisão, teremos o seguinte vetor de pesos $V_{2}$ :

$$
\mathrm{V}_{2}=[1,5 ; 3,0 ; 0,5 ; 0,75 ; 0,75 ; 0,75 ; 0,75 ; 2,0]
$$

\subsection{Análise dos resultados com os Pesos Ajustados}

Os resultados da comparação são apresentados a seguir:

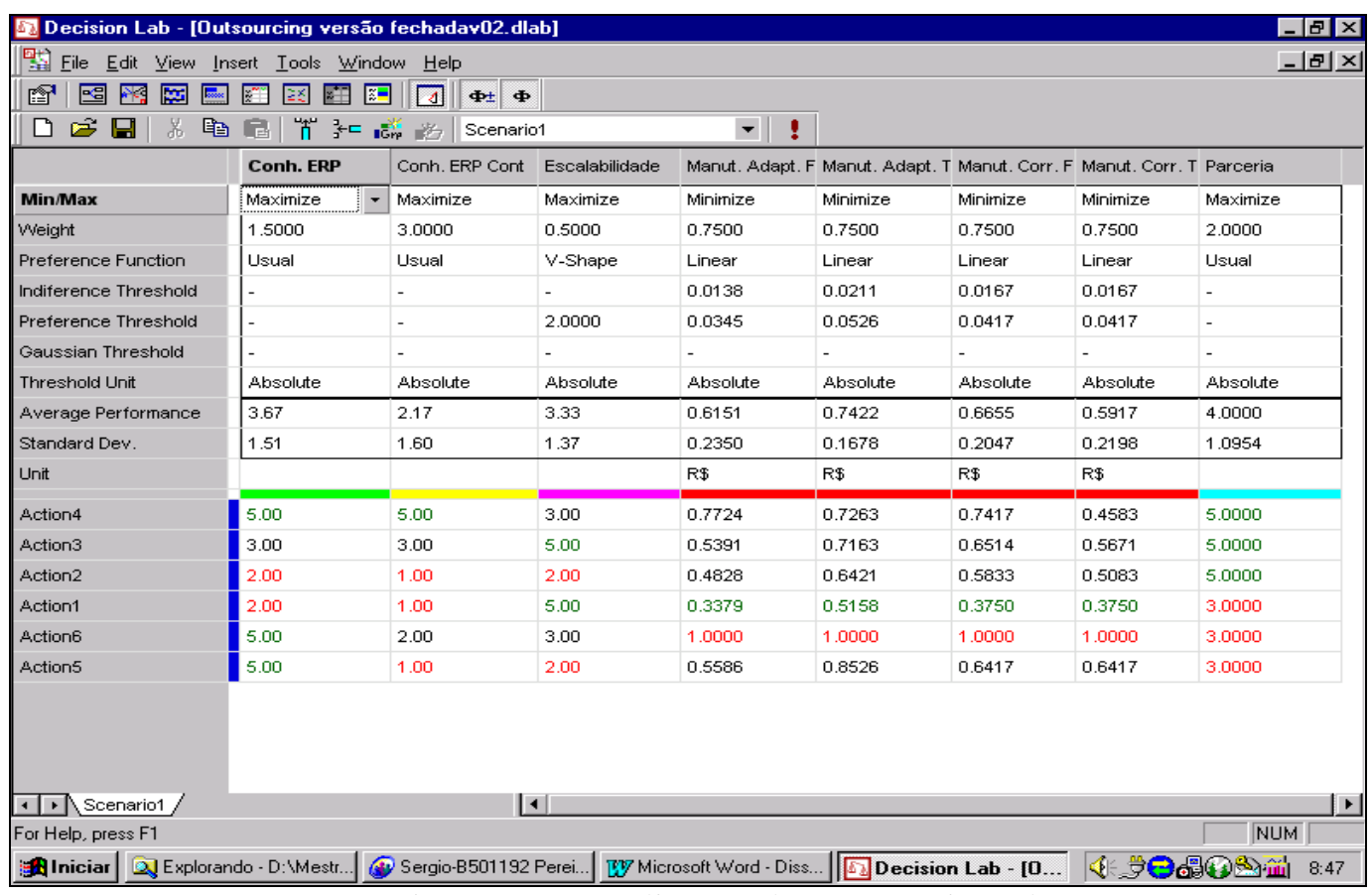

Figura 4: Normalização dos Pesos Ajustados 


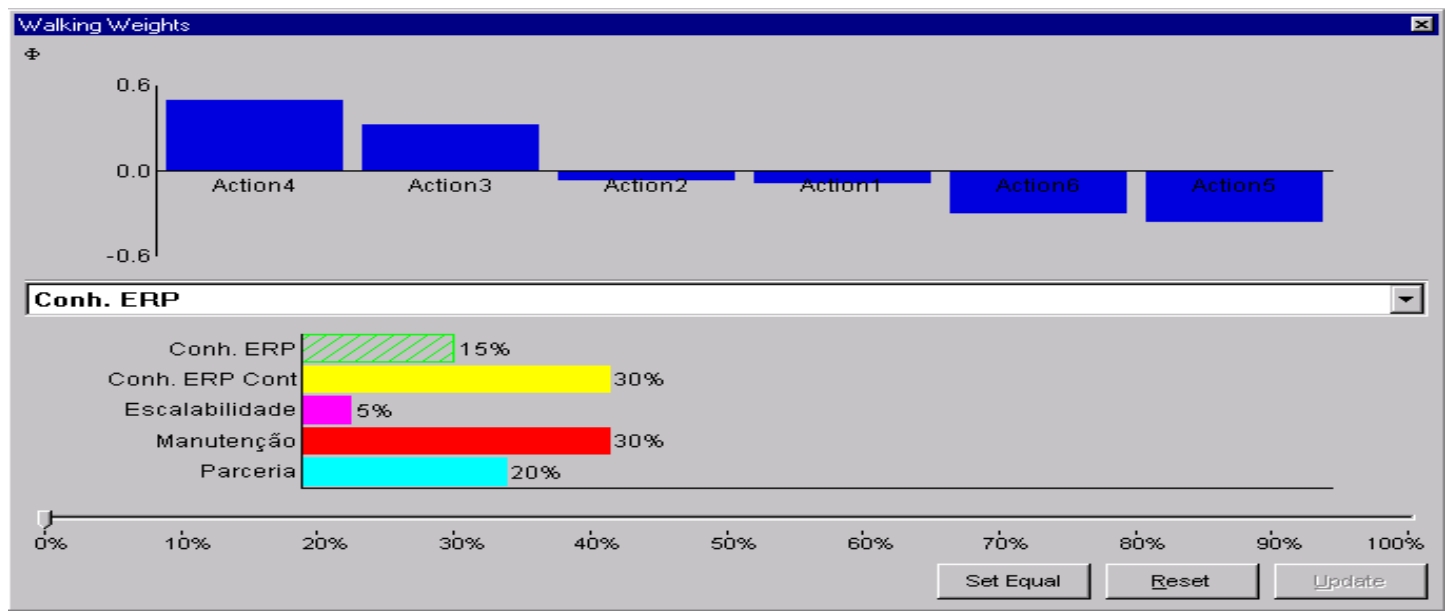

Figura 5: Resultados da comparação ajustado

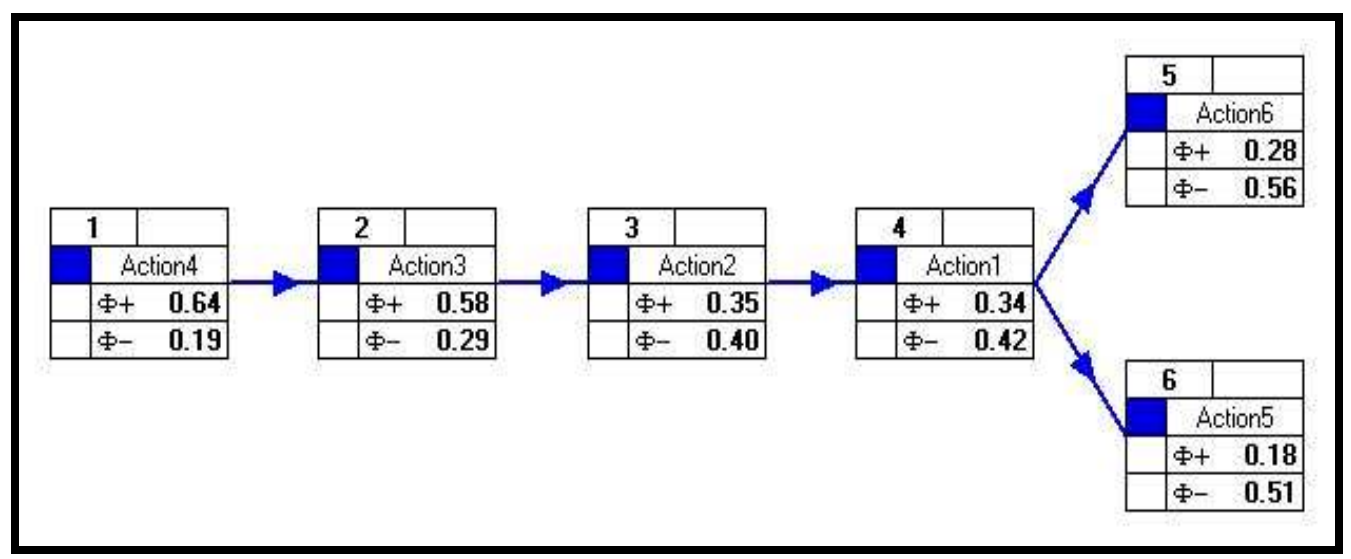

Figura 6: Classificação parcial ajustada

\section{RESULTADOS E ANÁLISE DE SENSIBILIDADE}

\subsection{Análise de Sensibilidade}

A análise de sensibilidade foi gerada pela ferramenta Decision Lab®:

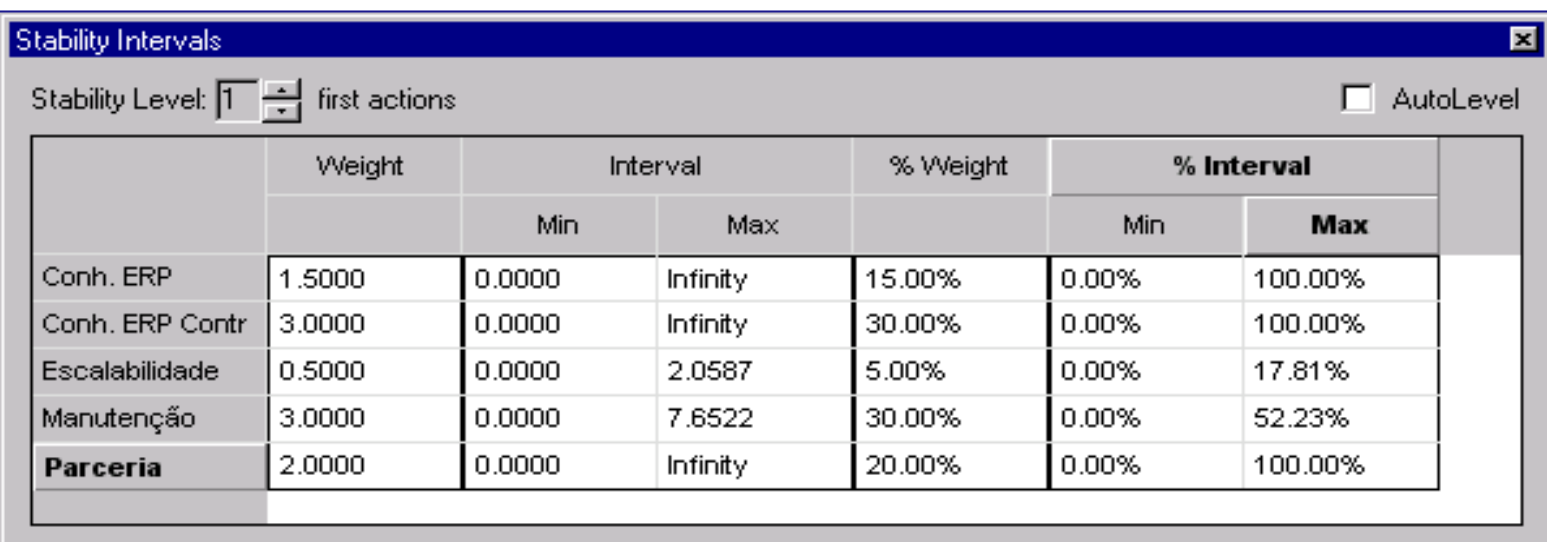

Figura 7: Análise de Sensibilidade 
Pela figura, verificamos que a validade do resultado mantém-se nos seguintes limites :

- Independe das variações isoladas dos pesos de Conhecimento ERP, Conhecimento ERP contratante e Parceria;

- Mantém-se com a variação isolada de peso de Escalabilidade entre 0 e 17,81\%.Acima disto, a ação preferida passa a ser a Action3;

- Mantém-se com a variação isolada de peso de Manut. Adaptativa Funcional entre 0 e 25,28\%. Acima disto, a ação preferida passa a ser a Action3;

- Mantém-se com a variação isolada de peso de Manut. Adaptativa Técnica entre 0 e 39,74\%. Acima disto, a ação preferida passa a ser a Action1;

- Mantém-se com a variação isolada de peso de Manut. Corretiva Funcional entre 0 e 26,57\%. Acima disto, a ação preferida passa a ser a Action3;

- Mantém-se com a variação isolada de peso de Manut. Corretiva Técnica entre 0 e 60,43\%. Acima disto, a ação preferida passa a ser a Action1;

\subsection{Comparação da Decisão Antes e Depois da Aplicação do Método}

O agente de decisão efetivamente não estava propenso a correr riscos na escolha de uma empresa para a prestação de serviços de manutenção. Em função disto, tendeu a escolher para a manutenção do sistema a mesma empresa que foi contratada para a condução da parametrização do pacote. Sua decisão, porém, estava fundamentada apenas na sua experiência. Como demonstra o trabalho, até mesmo na definição de pesos, a princípio , o agente de decisão estava direcionado a uma definição, buscando uma alternativa de preço. Ao analisar o resultado das comparações com os pesos iniciais, verificou que a definição de pesos focada em custos não correspondia a sua expectativa. Ao focar os pesos em parcerias e em conhecimento no ERP da contratante, pode verificar objetivamente em quais limites estava posicionada a sua aversão ao risco. No decorrer do trabalho, o foco dos pesos migrou de custos para a segurança.

Segundo Gomes et al. (2002) as vantagens da utilização dos métodos de apoio multicritério à decisão como quadro de referência analíticos são:

- Os métodos permitem uma abordagem mais abrangente e realista dos problemas complexos de decisão, pela modelagem de uma diversidade maior de fatores que se encontram envolvidos no processo decisório, tanto para critérios quantitativos quanto qualitativos;

- A utilização do método facilita a comunicação e integração entre as partes envolvidas no processo decisório;

- As preferências do agente de decisão ficam claramente explícitas com a utilização do método, permitindo maior organização e transparência do processo decisório, aumentando assim sua credibilidade;

- A utilização do método propicia maior compreensão das diversas dimensões do problema. Assim, o modelo inicial pode ser aprimorado, em função das discussões geradas durante o processo de tomada de decisão;

- A utilização do método agrega valor à informação, à medida que permite a abordagem de problemas considerados complexos e disponibiliza ao processo de tomada de decisão clareza e transparência;

O agente de decisão aprendeu sobre o problema, e pode explorar de maneira rápida e fácil, as alternativas de empresas, alterando a configuração de pesos. Com a utilização do método, foi possível a reavaliação dos critérios utilizados, a aplicação segura de uma decisão, a manutenção do histórico do que foi decidido e a definição dos limites em que esta decisão é válida. 


\section{CONCLUSÕES E RECOMENDAÇÕES}

A empresa estudada apresenta como característica uma forte terceirização de seus serviços, sendo o desenvolvimento e manutenção de sistema uma área em franco desenvolvimento. A utilização de métodos de apoio à decisão permite que todo o processo de decisão seja auditável, o que beneficia o entendimento da decisão tomada e a escolha e definição dos critérios utilizados. Com a utilização sistemática do método, será possível um ajuste cada vez melhor dos critérios utilizados, aprendendo com as experiências do passado para a geração de novos e melhores processos de decisão.

A utilização do método, além disso, formaliza um método único de apoio à decisão. Hoje, o processo de decisão é realizado de acordo com o analista que desenvolve o trabalho, sem padronização de forma.

No trabalho realizado, o agende de decisão ficou positivamente impressionado com a facilidade de manipulação do software Decision Lab, pela gama de relatórios e gráficos apresentados pela ferramenta, e pela possibilidade de simulação dos cálculos do Método Promethée utilizando planilhas Excel. O processo de aprendizado foi relativamente rápido e o resultado final foi a visibilidade de todas as vantagens da utilização do método, seja a transparência de critérios e preferências, a "memória de cálculo" da decisão, a organização e seleção dos critérios e a análise de sensibilidade. Ficou claro que o método permite a apresentação do problema e da decisão tomada pela gerência para outras áreas de TI e da empresa (departamento de compras, por exemplo), de uma maneira bastante objetiva.

A decisão final da avaliação não alterou a opinião inicial do agente da decisão. Isto porque a decisão, mesmo que intuitivamente, foi tomada sem a utilização da ferramenta. A ferramenta, porém permitiu que o agente da decisão soubesse claramente os limites da decisão e permitiu a explicitação dos critérios e pesos. O objetivo do trabalho foi apresentar uma alternativa ao agente da decisão, de maneira a permitir que o processo de decisão seja o mais claro possível, permitindo inclusive a visualização dos limites da decisão, o que pode, no futuro, inclusive, gerar a reavaliação dos critérios subjetivos, permitindo que o agente da decisão venha a questionar sua própria intuição.

As contribuições principais da utilização da ferramenta para a empresa são a padronização de linguagem, a explicitação do processo de pesos e critérios e a simplificação do processo hoje desenvolvido.

Futuros trabalhos podem ser desenvolvidos, seguindo esta mesma linha, levando em consideração a análise do problema para a identificação dos critérios relevantes. Consideramos que o processo de definição dos critérios, a quantificação de limites máximos e mínimos para cada critério, definição dos atores, a avaliação dos atores para cada critério e a definição dos pesos podem ser realizados para outros problemas da área de TI ou de outras áreas da empresa.

\section{REFERÊNCIAS BIBLIOGRÁFICAS}

BERNSTORFF, Vitor Hugo (2001) "Eficácia na Terceirização da Tecnologia da Informação: Aspectos de Controle". In: XXV Encontro da ANPAD, 2001, Curitiba. Anais: XXV Encontro da ANPAD

BRANS, Jean-Pierre, MARESCHAL, Bertrand (1994) “ The PROMETHEE-GAIA Decision Support System for Multicriteria Investigations". In: Investigacion Operativa, 4, p.107-117. 
BRANS, Jean-Pierre, MARESCHAL, Bertrand (2002) Prométhée-Gaia. Úne méthodologie d'aide à la décision en présence de critères multiples. Bruxelas. Editions de l'Université de Bruxelles. Statistique et Mathématiques Appliquées.

GOMES, Luiz Flávio Autran Monteiro, GOMES, Carlos Francisco Simões, DE ALMEIDA, Adiel Teixeira (2002) Tomada de Decisão Gerencial. Enfoque Multicritério. São Paulo. Editora Atlas.

SCHÄRLIG, Alain (1996) Pratiquer Electre et Prométhée. Un complément à Décider sur plusieurs critères. Lausanne. Presses polytechniques et universitaires romandes. Collection Diriger l'entreprise 11.

VINCKE, Philippe (1989) "Les Méthodes de Surclassement". In: VINCKE, P., L'aide Multicritère à la Decision, Bruxelas. Editions de l'Université de Bruxelles. Statistique et Mathématiques Appliquées, Cap. 5, p. 85-108. 